\title{
Can consumers' willingness to pay incentivize adoption of environmental impact reducing technologies in meat animal production?
}

\author{
Robin R. White ${ }^{\mathrm{a}, *}$, Michael Brady ${ }^{\mathrm{b}}$ \\ ${ }^{a}$ Department of Animal Sciences, Washington State University, Pullman, WA 99164, USA \\ ${ }^{\mathrm{b}}$ School of Economic Sciences, Washington State University, Pullman, WA 99164, USA
}

\section{A R T I C L E I N F O}

\section{Article history:}

Received 3 February 2014

Received in revised form 12 June 2014

Accepted 13 June 2014

\section{Keywords:}

Willingness to pay

Environmental impact

Meat production

Bayesian analysis

\begin{abstract}
A B S T R A C T
This study develops a model estimating consumer willingness to pay (WTP) for environmental meat attributes and uses a multi-objective nutritional optimizer to explore the extent to which WTP can offset on-farm costs of reducing water use. Data for the WTP model are sourced from a literature survey of the Agricola and Google Scholar databases yielding 46 studies estimating WTP for pure and impure (organic, grass-fed, natural) environmental meat attributes. Bayesian analysis is used to estimate 3 models varying in independent variables. Models are evaluated by the correlation coefficient $\left(R^{2}\right)$, root mean squared error of prediction (RMSPE) and posterior model probability. The most probable model is then used to estimate a confidence range of WTP for pure environmental beef. Impure environmental labels result in higher WTP than pure labels. Non-hypothetical WTP for pure environmental labeling for North American consumers ranges from $6.7 \%$ to $32.6 \%$. A case study is conducted to identify the expected reduction in water use that can be funded from capturing WTP through labeling. A multi-objective nutritional optimizer is used to identify ideal management of beef cattle to reduce whole-system water use in three regions of the United States. Cost increases from management are varied over the predicted range in WTP and combined with the probability of a consumer purchasing beef at each WTP value to identify the theoretical effect on expected environmental impact reduction. A 10\% premium is the ideal WTP, resulting in water use reductions between $24.4 \mathrm{~L}$ and $41.4 \mathrm{~L}$.
\end{abstract}

(c) 2014 Elsevier Ltd. All rights reserved.

\section{Introduction}

Global population is increasing (US Census Bureau, 2013; United Nations, 2011) and concurrent improvements in developing nations' affluence will increase global consumption of livestock products (Cranfield et al., 1998; Delgado, 2003). Livestock production is resource-intensive and agricultural water (Vorosmarty et al., 2000) and land (Lambin and Meyfroidt, 2011) availability is already limited. By 2050, food demand is predicted to outpace water availability in most regions of the world (Falkenmark et al., 2009) and the cost of agricultural land is expected to rise significantly (Hertel, 2011). Improving sustainability of livestock production is a frequently proposed solution to this global food production challenge.

\footnotetext{
* Corresponding author. Address: Department of Dairy Science (0315), Litton Reaves Hall Room 2470, Virginia Tech, 175 West Campus Drive, Blacksburg, VA 24061, USA. Tel.: +1 5097019290.

E-mail address: rwhite14@vt.edu (R.R. White).
}

Top-down regulatory policies are often suggested as a means of improving agriculture's sustainability (Deckers, 2010; Edjabou and Smed, 2013; Lybbert and Sumner, 2012). Many top-down policies mandate some reduction in environmental impact and incentivize or penalize beneficial or detrimental management practices (Golub et al., 2012). This approach often requires a substantial sacrifice of farm income (Varela-Ortega et al., 1998) because the policies fail to account for cost heterogeneity at the farm level. Improving sustainability of food production systems should balance environmental, economic and social focuses (National Research Council, 2011, 2013; WCED, 1987). Therefore a policy that has negative effects on farm revenue will not be sustainable. An alternative approach to decreasing agricultural environmental impact is manipulation of consumer purchasing decisions by policy, taxation or labeling (Deckers, 2010; Gadema and Oglethorpe, 2011; González et al., 2011). Demand for environmental labels on food products is increasing (Gadema and Oglethorpe, 2011). Before food labeling can be relied upon as an alternative policy option, studies should investigate the confidence range around estimates of consumer 
WTP for environmental meat labels and compare to cost increases associated with reducing environmental impact (e.g., White et al., 2013a, 2013b).

Consumers demonstrate willingness to pay (WTP) for meat products with perceived reductions in environmental impact (Hurley et al., 2006; Tonsor and Shupp, 2009). Much of the literature on environmental labeling focuses on impure environmental labels (organic, grass-fed, all natural, local, etc.) which have some personal health or safety attributes in addition to perceived environmental attributes. This focus makes it difficult to identify whether there is WTP for pure environmental meat attributes (i.e., reduced water use). Some studies do assess WTP for pure environmental labels (Hurley et al., 2006; Nilsson et al., 2006; Tonsor and Shupp, 2009) but variability in study methodology and the resulting effects on WTP estimates (List and Shogren, 1998) make it difficult to rely on any of these individual values as robust WTP estimate. Past studies rely on quantitative summary techniques to synthesize literature assessing WTP for a variety of attributes or utilizing several methodologies to better isolate WTP for a single attribute (Cicia and Colantuoni, 2010; Lagerkvist and Hess, 2011; Lusk et al., 2005). In this case, quantitative summary can be used to partition out WTP for health/safety from environmental attributes in impure environmental valuations to estimate WTP for pure environmental attributes while taking methodological variability into account. This WTP can be compared to estimates of production cost increases related to reducing water use within meat production systems (White et al., 2013a, 2013b). This comparison can then help assess efficacy of using a labeling approach to incentivize adoption of environmental impact reducing technologies.

In this study, we have two objectives: (1) to develop a robust estimate of consumer WTP for environmental meat attributes and (2) to use a hypothetical beef production case study to estimate whether WTP can offset on-farm costs of adopting water-reducing technologies. Section 'Theory' discusses the theoretical framework. Section 'Materials and methods' details data collection and quantitative analysis. Section 'Results and discussions' presents outcomes of the models and assesses impacts of WTP on opportunity to reduce beef's environmental impact. Finally, concluding remarks and future research directions are presented in Section 'Conclusions and policy implications'.

\section{Theory}

Standard utility theory for consumer behavior (Deaton and Muellbauer, 1980) assumes that consumers seek to maximize utility through consumption of food subject to a budget constraint. A common understanding of utility assumes that consumers value the attributes represented by a good rather than the good itself (Rosen, 1974). In a hedonic sense, consumers view individual food items as a bundle of attributes. Willingness to pay for individual food items is then based on the associated attributes of the items. Food attributes typically considered in economic analyses are those that provide private benefits in terms of nutrients and quality, the latter of which includes a range of characteristics including taste, texture, physical appearance, etc. Consumers in the United States (US) have demonstrated increasing demand and willingness to pay (WTP) for food products with pure or impure environmental good characteristics. Examples include dolphin safe tuna (Teisl et al., 2002), rainforest enhancing coffee (Rice and McLean, 1999), locally produced food (Darby et al., 2008, 2006), organic foods (Corsi and Novelli, 2002; Krystallis and Chryssohoidis, 2005), cage-free or free range eggs and poultry (Bennett and Larson, 1996) or grass-fed beef (Umberger et al., 2002). Each of these products is perceived by the consumer to contain attributes associated with some aspect of a sustainable food system. Although the existence of these markets is somewhat taken for granted now, each began with uncertainty about whether there were enough consumers willing to pay a premium for the proposed environmental good relative to conventional goods.

\section{Materials and methods}

A three part methodology was used. First, a literature search was employed to identify studies that assessed consumer WTP for pure or impure (organic, grass-fed, all natural, local, etc.) attributes of meat. Three models were then fit to these data using a Bayesian regression. The models employed different explanatory variables designed to separate WTP for pure environmental attributes from valuations assessing goods with additional health/ safety attributes. The models were evaluated and compared using the correlation coefficient, $R^{2}$, the root mean squared error of prediction, RMSPE, and the posterior model probability. The models were averaged based on their posterior probabilities and used to estimate a confidence range for non-hypothetical consumer WTP for pure environmental meat attributes. Finally, a multi-objective nutritional optimizer was used to explore whether WTP could offset increases in cost associated with adopting water-reducing management practices on-farm. The optimizer identified the range in water use reduction that was achievable within the bounds of consumer WTP.

\section{Data collection}

A literature search of the Agricola and Google Scholar databases was conducted using the keywords "consumer willingness to pay meat [beef/pork]". Studies were included if they presented a numerical estimate of consumer WTP for a meat attribute. Studies assessing pure or impure environmental attributes were identified as a subset from the literature search. Conference publications, white papers and extension oriented publications relating to consumer WTP for meat attributes were identified through the AgEconSearch engine again using the keywords "consumer willingness to pay meat [beef/pork]". Authors who had published several papers on WTP were contacted for copies of their most recent work. Studies were excluded from analysis if they presented WTP estimates from a dataset already included in analysis. Studies failing to present a numerical value of consumer WTP or assessing WTP for a cut of meat rather than a meat attribute were also excluded. Percentage premium WTP estimates were used in analysis to standardize over currencies and years. Therefore, if a base comparison value was not clearly stated within a study, it was excluded to eliminate bias from incorrect assumption of a base value. The selection process returned 61 studies representing 269 treatments conducted on over 34,000 consumers in 18 different countries. A total of 46 studies contained treatments assessing pure or impure environmental goods and 26 studies contained treatments that assessed a purely private meat attribute (quality, health, safety, etc.). As the values would suggest, some studies had both environmental and non-environmental valuations. Studies are summarized in the online supplement (Tables S.1 and S.2) organized alphabetically based on the first author's last name.

\section{Bayesian model fitting}

Bayesian regression analysis was used to fit three models varying in independent variables. Bayesian model fitting was used for several reasons. A large amount of explanatory variables were employed and Bayesian regression analysis is better equipped to deal with numerous explanatory variables (Gelman et al., 2004; 
Mitchell and Beauchamp, 1988). Additionally, a small sample size was anticipated and Bayesian model fitting, due to reliance on Markov Chain Monte Carlo simulation, is particularly well equipped to estimate models based on small datasets (Martin et al., 2011). Given the variability in the valuation techniques employed within the dataset, the models needed to account for study variability and differentiate between hypothetical and nonhypothetical valuation methods. Prior information was available about how study methodology influenced consumer WTP. To improve the predictive capacity of the model, the researchers wanted to include this prior information in the assessment. The use of priors in Bayesian analysis (Lenk and Orme, 2009) allowed for the information to be incorporated. Improperly specified informative priors can bias a model. To ensure this was not the case, an initial model fitting included both informative and non-informative priors. Comparison of the posterior probabilities, $R^{2}$ and RMSPE indicated informative priors improved probability, explained more variability in WTP and reduced model error.

All regression models followed the general form:

$y=X \beta+\varepsilon$ where $\varepsilon \sim N\left(0, \sigma^{2}\right)$

where $y$ is a matrix of dependent variable observations, $X$ is a matrix of independent variables with $\beta$ representing the regression coefficients. The error term $\varepsilon$ is normally distributed with mean zero and non-constant variance. The exact form of heteroskedasticity is not known but the error variances originate from the normal distribution. The coefficient $b$ and error $\sigma^{2}$ priors are specified as:

$$
\begin{aligned}
& b \sim N\left(b_{0}, B_{0}^{-1}\right) \\
& \sigma^{2} \sim \operatorname{Gamma}\left(c_{0} / 2, d_{0} / 2\right)
\end{aligned}
$$

Bayesian analysis uses iterative simulation that supplements the data available with information from the prior distribution based on Bayes theorem (Gelman et al., 2004). After data is inputted, the uncertainty in the model parameters is estimated by summarizing a set of random draws from each parameter vector based on a posterior distribution (Gelman et al., 2004). Because the posterior distribution is unknown, the Metropolis-Hastings algorithm, a Markov chain Monte Carlo method for random sampling of a probability distribution, is commonly used to estimate the distribution (Chib and Greenberg, 1995). The Metropolis algorithm is carried out in a series of steps (Chib and Greenberg, 1995). For each coefficient $\beta$, a desired probability distribution $P(\beta)$ exists. The algorithm is initialized by selecting an arbitrary point $P\left(\beta_{c}\right)$ and a probability density $Q(\beta \mid b)$ - these are based on the mean and standard error inputted as priors to the model. During each iteration, the next candidate for $\beta$ is selected from the distribution $Q\left(\beta \mid \beta_{o}\right)$. The acceptance ratio of the candidate, $P\left(\beta_{\mathrm{c}}\right) / P\left(\beta_{o}\right)$, is then calculated. If this ratio is greater than $1, \beta_{c}$ is more probable than $\beta_{o}$ and $\beta_{c}$ is accepted as the new value of the equation coefficient $\beta$. If less than 1 , then $\beta_{c}$ is rejected and $\beta_{o}$ is set to the new current value. This Markov process was carried out using $\mathrm{R}$ statistical software (Martin et al., 2011). The data from the literature search were supplemented with random samples from the prior distributions (Section 'Prior distributions') and the three models were estimated. For each model, the iteration process was continued for 500,000 iterations. To improve computational efficiency while maintaining estimation rigor, the first 5000 iterations were burned and every subsequent 2nd iteration was used for sampling. Because the algorithm accepts or rejects a value of $\beta$ based on the probability of the current and previous values, it is important to ensure enough iterations to allow the algorithm to converge on a highly probable value. Geweke (1993) identified one method of post hoc analysis to determine adequate convergence by testing equality of the means in the first and last part of a Markov chain. In this analysis we compared the first $10 \%$ of the chain and the last $50 \%$ (Geweke, 1993) to ensure convergence of each parameter.

\section{Regression models fit}

Three models were fit to explore how consumers might view pure and impure environmental labels. One model (M-P/IP) looked at characterizing meat attributes as either purely public or impure public. The M-P/IP classification was formed based on the assumption that consumers view environmental goods as either purely public (no direct personal benefit) or impure (some direct personal benefit). The authors hypothesized this structure would be too simplistic and so two additional models were considered. One model (M-CA) coded meat labels based on their constituent attributes (environmental, healthy, safe, local, etc.) following the theory that consumers value goods as a bundle of attributes. The final model (M-IL) coded each labeling scheme individually (environment only, grass-fed, organic, etc.). The M-IL scheme assumed each meat label had a unique bundle of constituent attributes inadequately explained by categorical variables like health or safety. In all models, the environmental term was used to represent pure environmental labeling.

\section{The dependent variable}

For all models, the dependent variable was the natural logarithm of the percentage premium WTP for the meat product attribute isolated in any particular treatment. Percentage premiums were used following the example of several previous WTP analyses to standardize across study year and currency type. In many cases, studies presented dollar value estimates of WTP premiums and a base price was sourced from the text. Base prices were either the average of the prices used in elicitation, the market price of the base product at the time of the study, or the WTP reported for a generic product, whichever was presented within the study. The online supplement (Table S.1) specifies the base prices used for each treatment along with the source of the base price.

\section{Explanatory variables}

The explanatory variables used in each model are listed in Table 1. In all models, a series of explanatory variables were included to account for the variability in study methodology, consumers assessed and study date. Study methodology is known to have substantial influence on the valuations obtained (List and Gallet, 2001). Studies conducted in-person lead to over-stated WTP estimates. In addition, studies assessing hypothetical and non-hypothetical valuation methods find that non-hypothetical valuations are lower (List and Shogren, 1998; Little and Berrens, 2004). To account for these methodological influences on WTP estimation binary dummy variables for in-person and nonhypothetical valuations were included.

Willingness to pay was expected to vary with meat type and cut. As studies on beef and pork were included in the assessment, a binary dummy was included identify studies on pork. Most studies assessed WTP for beef steak or pork chops, studies focusing on alternative products (ground beef) were coded separately to identify how meat cut affected WTP.

The data demonstrated a general trend of increasing percentage premium WTP with publication date. Ideally, data collection date would have been included in the assessment (Nelson and Kennedy, 2009); however, many studies failed to report the collection date and thus publication date was used as a proxy. Binary dummies to indicate half decade of publication were coded and used to explain the influence of publication date on WTP. Finally, WTP was expected to vary with location and gross domestic product per capita (GDP). Studies were categorized regionally. 
Table 1

Variable definitions.

\begin{tabular}{|c|c|c|c|c|c|c|}
\hline Variable & Definition & Models & Mean & SD & Min & Max \\
\hline GDP & Gross domestic product per capita ${ }^{a}$ & $1,2,3$ & 38,542 & 10,472 & 2441 & 59,889 \\
\hline GROUND & 1 If study tested a product other than beef steak or pork chops & $1,2,3$ & 0.167 & 0.3739 & 0 & 1 \\
\hline PORK & 1 If study tested a pork product; otherwise, 0 & $1,2,3$ & 0.331 & 0.471 & 0 & 1 \\
\hline 2000 & 1 If study was published after 1999 and before 2005; otherwise 0 & $1,2,3$ & 0.509 & 0.501 & 0 & 1 \\
\hline 2005 & 1 If study was published after 2004 and before 2010; otherwise 0 & $1,2,3$ & 0.257 & 0.438 & 0 & 1 \\
\hline 2010 & 1 If study was published after 2010 ; otherwise 0 & $1,2,3$ & 0.149 & 0.356 & 0 & 1 \\
\hline NAM & 1 If study was conducted in the US or Canada; otherwise, 0 & $1,2,3$ & 0.648 & 0.479 & 0 & 1 \\
\hline EUR & 1 If study was conducted in Europe; otherwise, 0 & $1,2,3$ & 0.272 & 0.446 & 0 & 1 \\
\hline ASIA & 1 If study was conducted in Asia; otherwise, 0 & $1,2,3$ & 0.048 & 0.214 & 0 & 1 \\
\hline INPERSON & 1 If study was conducted in person; otherwise 0 & $1,2,3$ & 0.603 & 0.490 & 0 & 1 \\
\hline NONHYP & 1 If study utilized a non-hypothetical valuation method; otherwise, 0 & $1,2,3$ & 0.369 & 0.484 & 0 & 1 \\
\hline IMPURE & 1 If study assessed an impure public good; otherwise, 0 & 1 & 0.472 & 0.500 & 0 & 1 \\
\hline ENV & 1 If study assessed a purely public, environmental good; otherwise, 0 & $1,2,3$ & 0.231 & 0.424 & 0 & 1 \\
\hline GRASS & 1 If study assessed grass-fed or grass-finished meat; otherwise, 0 & 3 & 0.052 & 0.223 & 0 & 1 \\
\hline ORGANIC & 1 If study assessed organic meat; otherwise, 0 & 3 & 0.044 & 0.206 & 0 & 1 \\
\hline NOHAG & $\begin{array}{l}1 \text { If study assessed meat produced without hormones, antibiotics and/or growth enhancing technologies; } \\
\text { otherwise, } 0\end{array}$ & 3 & 0.200 & 0.401 & 0 & 1 \\
\hline HEALTHY & 1 If study assessed an attribute associated with health; otherwise, 0 & 2 & 0.316 & 0.466 & 0 & 1 \\
\hline SAFE & 1 If study assessed an attribute associated with safety; otherwise 0 & 2 & 0.328 & 0.470 & 0 & 1 \\
\hline WELFARE & 1 If study assessed animal welfare; otherwise, 0 & 2,3 & 0.212 & 0.410 & 0 & 1 \\
\hline LOCAL & 1 If study assessed traceability, COOL labeling or local production; otherwise, 0 & 2,3 & 0.084 & 0.278 & 0 & 1 \\
\hline
\end{tabular}

a Gross domestic product was based on publication year and study location and sourced from World Bank (2014).

Geographical dummy variables were used to identify study location (US or Canada, Europe, Asia or other locations). To account for the expected personal wealth of individuals in each study, GDP was sourced based on location and publication year (World Bank, 2014).

\section{Prior distributions}

Informative prior distributions for the methodological coefficients were derived from a meta-regression analysis. Studies identified during the literature search process that tested purely private good attributes were set aside into a secondary dataset. This collection of studies is included in the online supplement (Table S.2). Studies were coded using the same methodological variables used in the Bayesian analysis. Random-effects meta-regression was used to fit a model predicting the natural log of percentage premium willingness to pay based on the methodological variables detailed in Section 'Explanatory variables'. Model fitting was done using $R$ statistical software (Viechtbauer, 2010). The resulting coefficients and variances were used to define informative prior distributions for the methodological variables. Non-informative priors were used for all subject specific variables because insufficient data was available to develop informative priors. Additionally, this helped avoid biasing the outcome with improperly specified priors. Informative priors are presented in Table 2.

\section{Model evaluation and comparison}

Models were evaluated using the correlation coefficient, $R^{2}$ and the root mean squared error of prediction, RMSPE. As each model was estimated, the Bayes factor of the model was calculated. After all models had been estimated, the posterior model probabilities were calculated (Kass and Raftery, 1995). The ranking of model probabilities as well as inferences from the most probable model were used to draw conclusions about consumer preferences. The best model was used to determine a range of WTP estimates for purely public and impure public environmental labeling schemes.

\section{Impact assessment}

One challenge with assessment of top-down regulatory policies is that they fail to account for cost structure at the farm level. To
Table 2

Informative priors used in analysis.

\begin{tabular}{lll}
\hline Variable & Mean & SE \\
\hline Intercept $^{\mathrm{a}}$ & 1.873 & 1.234 \\
GPD $^{\mathrm{a}}$ & $2.523 \times 10^{-5}$ & $1.854 \times 10^{-5}$ \\
$2000^{\mathrm{a}}$ & 0.413 & 0.6122 \\
$2005^{\mathrm{a}}$ & 0.964 & 0.728 \\
$2010^{\mathrm{a}}$ & 1.610 & 0.690 \\
GROUND $^{\mathrm{a}}$ & 0.098 & 0.467 \\
PORK $^{\mathrm{a}}$ & 0.577 & 0.371 \\
NAM $^{\mathrm{a}}$ & -0.564 & 0.471 \\
EUR $^{\mathrm{a}}$ & -2.076 & 0.578 \\
ASIA $^{\mathrm{a}}$ & 0.688 & 0.489 \\
INPERSON $^{\mathrm{a}}$ & -0.500 & 0.618 \\
NONHYP $^{\mathrm{a}}$ & 0.152 & 0.585 \\
IMPURE $^{\mathrm{b}}$ & 0 & 1 \\
ENV $^{\mathrm{b}}$ & 0 & 1 \\
WELFARE $^{\mathrm{b}}$ & 0 & 1 \\
LOCAL $^{\mathrm{b}}$ & 0 & 1 \\
SAFE $^{\mathrm{b}}$ & 0 & 1 \\
HEALTH $^{\mathrm{b}}$ & 0 & 1 \\
ORGANIC $^{\mathrm{b}}$ & 0 & 1 \\
GRASS $^{\mathrm{b}}$ & 0 & 1 \\
NOHAG $^{\mathrm{b}}$ & 0 & 1 \\
\hline
\end{tabular}

a Priors were calculated by random effects meta-regression.

b Priors are weakly informative following Gelman et al. (2004).

avoid this pitfall, we employ a multi-objective optimization model to assess how WTP could be used to offset on-farm management costs related to reducing water use. The optimizer was used to simulate beef production systems in three locations throughout the US The optimizer integrated environmental impact (Capper, 2011, 2012; White and Capper, 2013), farm economics (White and Capper, 2013), pasture management (McCall and Bishop-Hurley, 2003; Romera et al., 2009) and consumer willingness to pay. The model simulated a whole beef production system and adjusted cattle diets and pasture management strategies to reduce beef production's environmental impact while maintaining the production system within the bounds of biological, economic and practical constraints. Although presented in the context of a simulation, the cattle populations, production calendar, environmental impact and calculation of farm economics employed by this optimizer are thoroughly outlined in (White and Capper, 2013). A 
description of the weights and times for each cattle population is listed in the online supplement (Table S.3). Parameters used to determine the number of animals in each cattle population are given in the online supplement (Table S.4). Yield and quality of feedstuffs available in each region, as predicted by the pasture module (McCall and Bishop-Hurley, 2003; Romera et al., 2009), are included in the supplement Table S.5.

The production system was optimized using two different forms of objective function. The baseline scenario, least cost management, was simulated by optimizing:

$\operatorname{Minimize}(\operatorname{Cost})=F C+P C+L C$

where $F C$ (feed), $P C$ (pasture) and $L C$ (labor) costs were accounted based on the feedstuffs selected. After the least-cost baseline was simulated, environmental impact reducing scenarios minimizing water and land use were conducted. Both land and water were targeted because water use can easily be reduced by increasing land use (White et al., 2013a, 2013b); however, this is not practically feasible. These scenarios relied on the objective function:

$$
\begin{aligned}
& \text { Minimize }(O b j): \\
& O b j=\left(P V_{h 2 o}-B V_{h 20}\right) / B V_{h 20} \\
& O b j=\left(P V_{\text {land }}-B V_{\text {land }}\right) / B V_{\text {land }}
\end{aligned}
$$

The subscripts on the present $(P V)$ and base value $(B V)$ variables represent water use ( $h 20)$ or land use (land) per kilogram hot carcass beef produced. These values are calculated for the production system, based on the diets selected by the optimization process, following the equations enumerated in White and Capper (2013). The multi-objective function form followed Tozer and Stokes (2001). In each optimization, the choice variable was $D M I_{f, p}$. Nutrient requirements of each animal group in each month were used to ensure adequate nutrition without exceeding the maximum predicted dry matter intake:

$$
\begin{aligned}
& \sum_{f} D M I_{f, p} * M E_{f} \geqslant \text { MEreq }_{p} \\
& \sum_{f} D M I_{f, p} * M P_{f} \geqslant \text { NPreq }_{p} \\
& \sum_{f} D M I_{f, p} \leqslant D M I x_{p}
\end{aligned}
$$

where $D M I_{f, p}$ is intake of feed $(f) ; M E_{f}$ is the metabolizable energy content of feed $(f)$; MEreq $q_{a}$ is the metabolizable energy requirement of the animal (National Research Council, 2000); $M P_{f}$ is the metabolizable protein content of each feed $(f) ; M_{p r e q}$ is the metabolizable protein requirement for an animal (National Research Council, 2000), DMIx is maximum predicted dry matter intake. These values can be found in the online supplement (Table S.5). Increases in cost associated with reducing water use were restricted to less than WTP:

$B V_{\cos t}+B V_{\cos t}+\mathrm{WTP} \geq P V_{\cos t}$

where $P V_{\text {cost }}$ is cost simulated, WTP is the willingness to pay for low-environmental impact beef and $B V_{\text {cost }}$ is baseline cost. The WTP was varied within the confidence range of the averaged regression model. Consumer WTP was back-calculated to the farm level assuming a $65 \%$ conversion of retail beef to hot carcass weight beef (Schweihofer, 2012) and a conveyance rate of $25 \%$ of consumer WTP returning to the farm-level. The reductions in water use predicted by the optimizer were assumed to be the theoretical environmental impact reduction possible.

Given that only a portion of the population will pay a premium for environmental attributes, the WTP range was used to develop a cumulative normal distribution estimating probability of purchase at any given WTP value. The product of the theoretical environmental impact reduction and the predicted probability of purchase was used as an estimate of the realistic opportunity to reduce environmental impact.

\section{Results and discussions}

The predicted model variable coefficients and standard errors are included in Table 3. Model fit parameters are also reported. Analysis of the convergence indicated significant evidence of convergence for all coefficients in all models.

\section{Willingness to pay model comparison and evaluation}

Three models were fit to explore how consumers might view pure and impure environmental labels. The M-IP model with the lowest error and highest $R^{2}$. This could be the case for several reasons; most likely, each label has its own individual bundle of goods perceived by consumers but these unique bundles were insufficiently explained by healthy, local, welfare, safe and environmental attributes. Alternatively, the combination of attributes together may be of greater value to the consumer than the sum of the individual attribute values. Evaluation of the log marginal likelihood also yielded strong evidence (Kass and Raftery, 1995) for the hypothesis that consumers view each label as an individual good over the explanations provided by other models.

\section{Estimating consumer willingness to pay}

The models indicated WTP was influenced by study methodology, meat type, location and environmental label.

\section{Environmental labels and WTP}

For the purpose of comparison, North American consumers WTP for pure and impure (local, all natural, grass-fed, organic) environmental labeling, as calculated by the most probably model, is shown in Fig. 1. On average consumers would pay a $29.1 \%$ premium for impure environmental products (range: 13.9-64.3\%); pure environmental products only garnered a $14.8 \%$ premium (range: 6.7-32.6\%). As was expected, the impure labels resulted in higher WTP than pure environmental labels.

When the impure environmental labels were assessed individually, some interesting dynamics were revealed. Consumer WTP for grass-fed, natural and local products were the highest of any impure environmental attribute. Martinez (2008) analyzed retail price data and found that company-specific (natural, grass-fed, organic and/or food safety) labeling schemes resulted in the highest price premiums for beef cuts compared with other labeling schemes. These branding schemes garnered premiums from $48 \%$ to $84 \%$. The premiums for grass-fed and natural meat products predicted in this study were on the low end of this range but likely represent a realistic average WTP given that relatively small portions (collectively, $3 \%$ ) of the population actually pay the listed retail premium for these specialty products (Mathews Jr. and Johnson, 2013).

Scanner data analyses consistently show high price premiums for organic products (Martinez, 2008; Schulz et al., 2012). Schulz et al. (2012) found organic labeling increased beef cost by $\$ 6.56 /$ $\mathrm{kg}$. This WTP represents a $46.7 \%$ premium when compared to the intercept (or base) price of $\$ 14.06 / \mathrm{kg}$. Our model predicts premiums of $4.2-30.0 \%$ for organic products. The upper range of our confidence estimate is not within the range described by scanner data. This under-prediction could be because consumers purchasing organic are more concerned with the natural properties of the product (no hormones, no antibiotics or genetically modified organisms) and therefore the true WTP for organic products is 
Table 3

Model $^{\mathrm{a}}$ coefficients and goodness-of-fit parameters.

\begin{tabular}{|c|c|c|c|}
\hline Parameter & M-P/IP & $\mathrm{M}-\mathrm{CA}$ & M-IL \\
\hline Intercept & $2.24(1.21,3.27)$ & $2.254(1.236,3.274)$ & $1.924(0.852,3.004)$ \\
\hline GDP & $2.84 \times 10^{-5}\left(9.57 \times 10^{-6}, 4.72^{-5}\right)$ & $2.55 \times 10^{-5}\left(6.48 \times 10^{-6}, 4.48 \times 10^{-5}\right)$ & $3.14 \times 10^{-5}\left(1.18 \times 10^{-5}, 5.12 \times 10^{-5}\right)$ \\
\hline 2000 & $0.896(0.314,1.478)$ & $0.839(0.255,1.427)$ & $0.934(0.332,1.541)$ \\
\hline 2005 & $0.004(-0.593,0.606)$ & $-0.081(-0.685,0.528)$ & $-0.027(-0.655,0.610)$ \\
\hline 2010 & $0.467(-0.233,1.173)$ & $0.524(-0.206,1.266)$ & $0.650(-0.082,0.1392)$ \\
\hline GROUND & $-0.617(-1.076,-0.151)$ & $-0.627(-1.119,-0.129)$ & $-0.733(-1.238,-0.220)$ \\
\hline PORK & $0.305(-0.062,0.674)$ & $0.245(-0.142,0.637)$ & $0.214(-0.180,0.613)$ \\
\hline NAM & $-0.534(-1.201,0.130)$ & $-0.499(-1.166,0.165)$ & $-0.545(-1.216,0.118)$ \\
\hline EUR & $-0.712(1.386,-0.040)$ & $-0.735(-1.408,-0.065)$ & $-0.876(-1.558,-0.195)$ \\
\hline ASIA & $0.411(-0.364,1.189)$ & $0.412(-0.367,1.189)$ & $0.457(-0.324,1.238)$ \\
\hline INPERSON & $-0.373(-0.841,0.092)$ & $-0.389(-0.865,0.082)$ & $-0.348(-0.828,0.128)$ \\
\hline NONHYP & $-0.536(-1.097,0.026)$ & $-0.541(-1.104,0.030)$ & $-0.599(-1.160,-0.031)$ \\
\hline IMPURE & $0.404(-0.092,0.900)$ & & \\
\hline ENV & $0.045(-0.465,0.558)$ & $-0.086(-0.734,0.562)$ & $0.040(-0.748,0.830)$ \\
\hline WELFARE & & $0.370(-0.106,0.840)$ & $0.643(0.51,1.223)$ \\
\hline LOCAL & & $0.389(-0.137,0.911)$ & $0.457(-0.088,0.997)$ \\
\hline SAFE & & $-0.007(-0.600,0.583)$ & \\
\hline HEALTH & & $0.540(-0.156,1.236)$ & \\
\hline ORGANIC & & & $1.069(0.036,2.097)$ \\
\hline GRASS & & & $-0.250(-1.227,0.731)$ \\
\hline NOHAG & & & $0.578(-0.004,1.159)$ \\
\hline$R^{2}$ & 0.403 & 0.429 & 0.455 \\
\hline RMSPE & 49.16 & 42.92 & 28.77 \\
\hline LogML & -271.2 & -274.2 & -265.8 \\
\hline
\end{tabular}

${ }^{\text {a }} \mathrm{M}-\mathrm{P} / \mathrm{IP}$ assumed consumers valued goods only based on their impure/pure public good classification. M-CA assumed goods were values based on their constituent parts M-IL assumed each good label was valued individually.

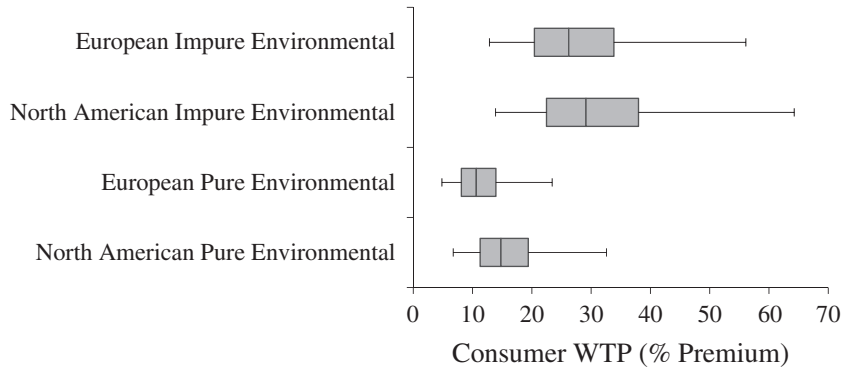

Fig. 1. 95\% Confidence ranges for North American or European consumers' willingness to pay for pure and impure environmental labeling of beef products. The boxes represent the range between $25 \%$ and $75 \%$ confidence with the mean indicated by the middle bar. The error bars represent $95 \%$ confidence.

reflected by the natural category in our model. Alternatively, there were very few studies assessing WTP for organic products (likely because they are already available on the market) and our sample may have been insufficient to adequately characterize WTP for organic meats.

\section{Methodological and meat type effects}

Previous literature indicates studies conducted in person or using non-hypothetical valuation methods result in over-estimation of WTP (List and Gallet, 2001; List and Shogren, 1998; Lusk et al., 2005). The model generated in this analysis agrees with these previous studies. When North American consumers' WTP for a pure environmental beef steak product was tested, in-person valuations lead to an $11.2 \%$ decrease in WTP and non-hypothetical valuation decreased the WTP estimate by $17.2 \%$.

Location and beef type influences on WTP for a pure environmental product are depicted in Fig. 2. Pork chops and beef steak had similar predicted WTP premiums. Cicia and Colantuoni (2010) found that consumers were willing to pay a 5.94\% lower premium for pork products. Cicia and Colantuoni studied WTP for traceable meat products. It is possible that differences in WTP for beef and pork observed in that study were due to concerns with

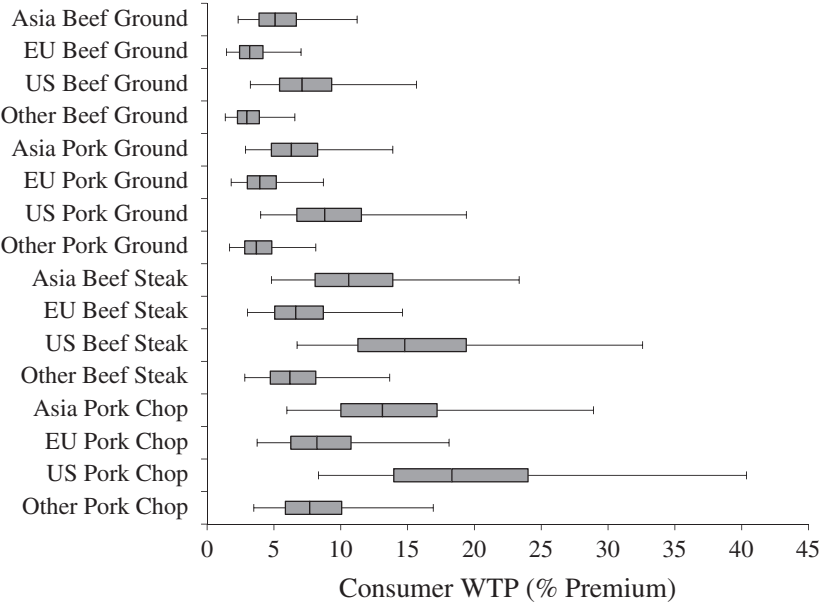

Fig. 2. A comparison of the $95 \%$ confidence ranges for pure environmental products when meat type, GDP and location parameters were varied. The boxes represent the range between $25 \%$ and $75 \%$ confidence with the mean indicated by the middle bar. The error bars represent $95 \%$ confidence.

bovine spongiform encephalopathy related to beef raised in some countries. When an environmental meat attribute was tested rather than an attribute implicitly related to human health, beef and pork environmental attributes are valued similarly. Interestingly, consumers were predicted to pay much higher premiums for chops and steaks than they would for ground products. This may be because chops and steaks are high quality and therefore consumers are prepared to ensure they purchase the best product possible.

The greater WTP for steaks and chops is of concern when exploring the options to rely on food labeling to help improve meat environmental impact. Without a substantial WTP for all products on the carcass, there may be minimal incentive to adjust production practices. Packers and retailers may prove key players in the use of labeling to improve meat production water use. As consumer preferences have become better understood, packers and 
retailers have adjusted their WTP for meat animals to better reflect the desires of the consumer (Igo et al., 2013). For example, consumers consistently show high WTP for tender, high quality steak grades (Schulz et al., 2012). Although an equivalent WTP does not exist for tender ground beef, packers, retailers and even feedlot operators will pay premiums for cattle with superior genetics for tenderness (Igo et al., 2013). As such, the intervention of packer or retailer WTP, in response to better understanding of consumer WTP, may help to more effectively incentivize adoption of water conserving production practices.

\section{Gross domestic product and regional effects}

When GDP was held constant, both North American and European consumers had substantially lower WTP than Asian consumers. North American consumers had higher WTP than European consumers. Similar WTP between North American and European consumers was expected because surveys conducted in Europe (Fotopoulos and Krystallis, 2002), North America (Dettmann and Dimitri, 2009) and elsewhere (Aguirre, 2007) find similar characteristics in consumers interested in environmentally-labeled products. The comparative regional dynamics in Cicia and Colantuoni (2010) and Lusk et al. (2005) concur with those outlined here; however, Yu and Gao (2010) found European consumers had lower WTP than North American consumers. Additionally, the high WTP predicted for Asian consumers does not agree well with the WTP estimates generated by Yu and Gao (2010) and Lusk et al. (2005). This may be because none of the studies had a large number of samples from Asian consumers (2 studies in Lusk et al. (2005), 3 studies in Yu and Gao (2010) and 4 in this study). With so few estimates of Asian consumers WTP, the high between-study variability in WTP estimates is to be expected.

When GDP was varied and regional dummies were held constant, GDP had a substantial, positive impact on WTP. For every $\$ 1000$ increase in GDP, WTP increased 1.03\%. Previous studies use GDP as a measure of welfare across countries (Jones and Klenow, 2010). It is frequently hypothesized that as GDP increases, welfare will improve, citizens will become more altruistic and more willing to donate to public goods like environmental protection (Duroy, 2008). The current body of literature finds very diverse relationships (positive linear, negative linear, marginal linear, quadratic, etc.) between GDP and environmental donations (Duroy, 2008; Menges et al., 2005) or environmental good purchases (Vigani and Olper, 2013). This study indicates that as GDP increases, consumers do appear to be willing to partition more of their budget toward impure or pure environmental goods. This differs from most previous studies finding a negative or quadratic effect possibly because impure environmental goods were included and the analysis did not strictly test donations to a purely environmental good.

\section{Implications of WTP on beef environmental impact}

\section{Baseline scenarios by region}

A multi-objective nutritional optimizer was used to explore the extent to which consumer WTP could offset increases in production costs attributed to reducing whole-system water use. Three

Table 4

Baseline operating costs, water use and land use to produce beef in each region.

\begin{tabular}{lccc}
\hline Baseline & Pacific Northwest & South & Midwest \\
\hline Cost $(\$ / \mathrm{kg} \mathrm{HCW})$ & 1.47 & 1.45 & 1.46 \\
Water $(\mathrm{L} / \mathrm{kg} \mathrm{HCW})$ & 711.3 & 900.4 & 708.8 \\
Land $\left(\mathrm{m}^{2} / \mathrm{kg} \mathrm{HCW}\right)$ & 31.9 & 16.3 & 61.7 \\
\hline
\end{tabular}

different regions were simulated to account for some of the costheterogeneity that exists at the farm level. Baseline production costs, water use and land use are included in Table 4. Production costs to yield a $\mathrm{kg}$ of hot carcass weight (HCW) beef were relatively homogeneous $( \pm 0.02)$ across regions in the least-cost baseline scenario. Land use and water use between the regions exhibited more variability. Substantial regional variability in environmental impact attributable to beef production was also found in previous studies (Pelletier et al., 2010; Peters et al., 2010a, 2010b; Stackhouse-Lawson et al., 2012). In this study, most of the variability was due to differences in pasture yield as dictated by variable rainfall and solar radiation in each region.

\section{Total water use reductions}

The optimizer was used to assess how opportunity to decrease water use changed as WTP increased. Water use predicted by the optimizer for each region is included in Table 4. Water use decreased at a decreasing rate as WTP increased (Fig. 3). Regions demonstrated unique inflection points and different opportunities to improve water use. In the Pacific Northwest and the Midwest, substantial reductions in water use were achieved $(55.4 \mathrm{~L} / \mathrm{kg}$ HCW beef or $63.8 \mathrm{~L} / \mathrm{kg} \mathrm{HCW}$ beef). A premium WTP of about $20 \%$ was required in the Pacific Northwest while only a $15 \%$ premium was required in the Midwest. In the South, water use could only be reduced by $39.1 \mathrm{~L} / \mathrm{kg} \mathrm{HCW}$ beef. This reduction required a $23 \%$ premium WTP.

\section{Effects of probability of purchase on reducing water}

The cumulative normal distribution outlined by the WTP 95\% confidence interval was used to calculate probability of purchase across the WTP range. The probability began to decrease substantially as WTP increased to about $10 \%$. Probability of purchase reached nearly 0 at WTP $30 \%$. Theoretical opportunities to reduce water use were calculated as the product of the environmental impact reduction and the probability of purchase at each WTP value. The curves for theoretical water use reduction are included in Fig. 4. Regions demonstrated different opportunities to reduce water use but the ideal WTP was $10 \%$ in all regions. For reference, a $10 \%$ premium equates to $\$ 1.10 / \mathrm{kg}$ given the average retail price of beef in the US (USDA/ERS, 2013). At the farm-level, this WTP translates to a $\$ 0.17$ increase in operating costs per $\mathrm{kg} \mathrm{HCW}$ beef produced or $\$ 52.77$ per mature breeding cow per year. The Midwest had the greatest opportunity to reduce water use $(41.4 \mathrm{~L} / \mathrm{kg}$

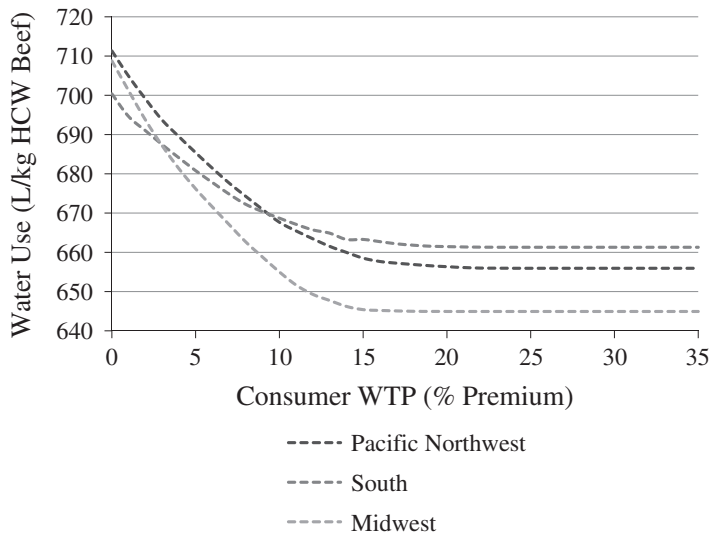

Fig. 3. Water use attributed to a whole-farm beef production system over a schedule of allowable increases in operating costs. Operating cost increases were constrained to less than consumer WTP. Consumer WTP was varied within the confidence range for North American consumers WTP for pure environmental beef products. 


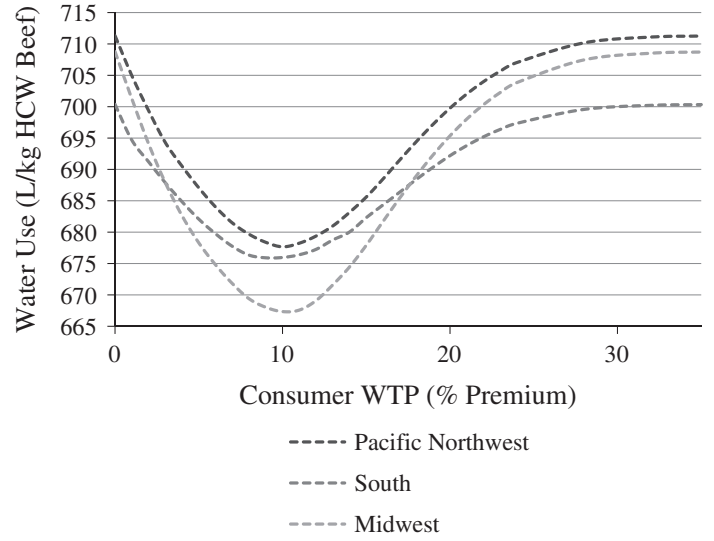

Fig. 4. Water use attributed to a whole-farm beef production system over a schedule of allowable increases in operating costs when probability of purchase was factored in. Probability of purchase was calculated from a cumulative normal distribution based on the confidence range for North American consumers WTP for pure environmental beef products.

HCW beef). The Pacific Northwest and the South had lower opportunities (33.6 L/HCW beef or $24.4 \mathrm{~L} / \mathrm{HCW}$ beef).

In the US in $2013,11.82 \times 10^{9} \mathrm{~kg}$ HCW beef were produced. When applied at the national scale, the water reductions calculated in this study would conserve between $2.89 \times 10^{11} \mathrm{~L}$ and $4.90 \times 10^{11}$ L per year. In the US, a frequent estimate of daily water use per person is $378 \mathrm{~L}$ ( $100 \mathrm{US}$ gallons). In practical terms, these water use reductions would enough water to supply the annual usage of $2.09 \times 10^{6}$ to $3.55 \times 10^{6}$ people.

\section{Conclusions and policy implications}

Improving sustainability is a promising solution to the global food production challenge. Attempts to employ top-down regulatory policies to mandate improvements in meat production sustainability may be unsuccessful because these policies frequently fail to account for farm level cost heterogeneity. This study investigated opportunities to rely on food labeling as an alternative means of incentivizing adoption of water-reducing technologies in meat animal production. The approach relied on estimating a confidence range for consumers' WTP for pure environmental meat attributes and subsequently using that confidence range and a farm system optimizer to identify optimal on-farm nutritional management of beef cattle to reduce water use. The WTP assessment found WTP was significantly influenced by demographic factors and study methodology. Importantly, WTP for pure environmental products was substantially less than WTP for impure environmental products. The resulting range in consumers' WTP was then used to test the extent to which WTP could offset on-farm costs of reducing water use in three regions across the US. The optimizer detected different opportunities to decrease water use in each region. Probability of purchase was factored into the analysis to make a realistic statement about the extent to which food labeling would influence management practices. The ideal consumer WTP was $10 \%$ and water conservation of $24.4-$ 41.4 L was possible.

This analysis identified several important points. First, there is a WTP for pure environmental meat attributes, distinct from currently available impure environmental products (organic, grass-fed, etc.). This is imperative because consumers have many misconceptions about food labeling (Gadema and Oglethorpe, 2011). Although consumers perceive that impure environmental products reduce the environmental impact of meat production, frequently these systems are less efficient than conventional meat production (Capper, 2012) and as a result, they have higher environmental impacts per $\mathrm{kg}$ product (Capper and Bauman, 2013). Additionally, small premiums paid at a retail level, if even conveyed $25 \%$ to the farm level, can offset operating cost increases attributable to decreasing water use. Many studies have identified management practices that will reduce environmental impact; however, producers are leery to adopt these practices because farm-level economic analysis is rarely included in the assessment. By demonstrating how WTP premiums could feed back to offset operating costs, this study integrates on-farm economic analysis with environmental impact reduction. As a final contribution, this study demonstrated moderate WTP increases that are palatable to the average consumer will have a greater aggregated impact on reducing water use than niche products with excessively high retail prices. This finding suggests that when using a labeling approach to reduce water use, the objective should not be to pioneer a new niche product but rather, to appeal to the majority of consumers.

\section{Appendix A. Supplementary material}

Supplementary data associated with this article can be found, in the online version, at http://dx.doi.org/10.1016/j.foodpol.2014.06. 007.

\section{References}

Aguirre, J.A., 2007. The farmer's market organic consumer of Costa Rica. Br. Food J. 109, 145-154.

Bennett, R., Larson, D., 1996. Contingent valuation of the perceived benefits of farm animal welfare legislation: an exploratory survey. J. Agric. Econ. 47, 224-235.

Capper, J.L., 2011. The environmental impact of beef production in the United States: 1977 compared with 2007. J. Anim. Sci. 89, 4249-4261.

Capper, J.L., 2012. Is the grass always greener? comparing the environmental impact of conventional, natural and grass-fed beef production systems. Animals 2, 127-143.

Capper, J.L., Bauman, D.E., 2013. The role of productivity in improving the environmental sustainability of ruminant production systems. Ann. Rev. Anim. Biosci. 1, 469-489.

Chib, S., Greenberg, E., 1995. Understanding the metropolis-hastings algorithm. Am. Stat. 49, 327-335.

Cicia, G., Colantuoni, F., 2010. Willingness to pay for traceable meat attributes: a meta-analysis. Int. J. Food Syst. Dyn. 1, 252-263.

Corsi, A., Novelli, S. 2002. Consumers' willingness to pay a price for organic beef meat. In: Proceedings of the EAEE Congress. Zargoza, Spain, vol. 28, pp. 31-48.

Cranfield, J.A., Hertel, T.A., Eales, J.S., Preckel, P.V., 1998. Changes in the structure of global food demand. Am. J. Agric. Econ. 80, 1042-1050.

Darby, K., Batte, M.T., Ernst, S., Roe, B., 2006. Willingness to pay for locally produced foods: a customer intercept study of direct market and grocery store shoppers. Am. Agric. Econ. Assoc., 1-31.

Darby, K., Batte, M.T., Ernst, S., Roe, B., 2008. Decomposing local: a conjoint analysis of locally produced foods. Am. J. Agric. Econ. 90, 476-486.

Deaton, A., Muellbauer, J., 1980. An almost ideal demand system. Am. Econ. Rev. 70, $312-326$.

Deckers, J., 2010. Should the consumption of farmed animal products be restricted, and if so, by how much? Food Policy 35, 497-503.

Delgado, C.L., 2003. Rising consumption of meat and milk in developing countries has created a new food revolution. J. Nutr. 188, 89075-89105.

Dettmann, R.L., Dimitri, C., 2009. Who's buying organic vegetables? demographic characteristics of US consumers. J. Food Prod. Mark. 16, 79-91.

Duroy, Q.M., 2008. Testing the affluence hypothesis: a cross-cultural analysis of the determinants of environmental action. Soc. Sci. J. 45, 419-439.

Edjabou, L.D., Smed, S., 2013. The effect of using consumption taxes on foods to promote climate friendly diets-the case of Denmark. Food Policy 39, 84-96.

Falkenmark, M., Rockstrom, J., Karlberg, L., 2009. Present and future water requirements for feeding humanity. Food Security 1, 59-69.

Fotopoulos, C., Krystallis, A., 2002. Purchasing motives and profile of the Greek organic consumer: a countrywide survey. Br. Food J. 104, 730-765.

Gadema, Z., Oglethorpe, D., 2011. The use and usefulness of carbon labelling food: a policy perspective from a survey of UK supermarket shoppers. Food Policy 36, $815-822$.

Gelman, A., Carlin, J., Stern, H., Rubin, D., 2004. Bayesian Data Analysis. CRC Press, Bota Roca, Florida.

Geweke, J., 1993. Bayesian treatment of the independent student-t linear model. J. Appl. Econ. 8, S19-S40.

Golub, A.A. et al., 2012. Global climate policy impacts on livestock, land use, livelihoods, and food security. Proc. Natl. Acad. Sci. USA. 
González, A.D., Frostell, B., Carlsson-Kanyama, A., 2011. Protein efficiency per unit energy and per unit greenhouse gas emissions: potential contribution of diet choices to climate change mitigation. Food Policy 36, 562-570.

Hertel, T.W., 2011. The global supply and demand for agricultural land in 2050: a perfect storm in the making? Am. J. Agric. Econ. 93, 259-275.

Hurley, S.P., Miller, D.J., Kliebenstein, J.B., 2006. Estimating willingness to pay using a polychotomous choice function: an application to pork products with environmental attributes. J. Agric. Res. Econ. 31, 301-317.

Igo, J.L. et al., 2013. Phase 1 of the national beef quality audit-2011: quantifying willingness-to-pay, best-worst, scaling and current status of quality characteristics in different beef industry marketing sectors. J. Anim. Sci. 91 1907-1919.

Jones, C.I., Klenow, P.J., 2010. Beyond GDP? Welfare Across Countries and Time. National Bureau of Economic Research.

Kass, R.E., Raftery, A.E., 1995. Bayes factors. J. Am. Stat. Assoc. 90, 773-795.

Krystallis, A., Chryssohoidis, G., 2005. Consumers' willingness to pay for organic food: factors that affect it and variation per organic product type. Br. Food J. 107, 320-343.

Lagerkvist, C.J., Hess, S., 2011. A meta-analysis of consumer willingness to pay for farm animal welfare. Eur. Rev. Agric. Econ. 38, 55-78.

Lambin, E.F., Meyfroidt, P., 2011. Global land use change, economic globalization and the looming land scarcity. Proc. Natl. Acad. Sci. USA 108, 3465-3472.

Lenk, P., Orme, B., 2009. The value of informative priors in Bayesian inference with sparse data. J. Mark. Res. 46, 832-845.

List, J.A., Gallet, C.A., 2001. What experimental protocol influence disparities between actual and hypothetical stated values? Environ. Res. Econ. 20, 241 254.

List, J.A., Shogren, J.F., 1998. Calibration of the difference between actual and hypothetical valuations in a field experiment. J. Econ. Behav. Org. 37, 193-205.

Little, J., Berrens, R., 2004. Explaining disparities between actual and hypothetical stated values: further investigation using meta-analysis. Econ. Bull. 3, 1-13.

Lusk, J.L., Jamal, M., Kurlander, L., Roucan, M., Taulman, L., 2005. A meta-analysis of genetically modified food valuation studies. J. Agric. Res. Econ. 30, 28-44.

Lybbert, T.J., Sumner, D.A., 2012. Agricultural technologies for climate change in developing countries: policy options for innovation and technology diffusion. Food Policy 37, 114-123.

Martin, A.D., Quinn, K.M., Park, J.H., 2011. MCMCpack: Markov Chain Monte Carlo in R. J. Stat. Softw. 42, 1-21.

Martinez, S.W. 2008. Estimating the value of retail beef product brands and other attributes. In: Selected Paper Prepared for Presentation at the American Agricultural Economics Association Annual Meeting, Orlando, FL, July, pp. 27-29.

Mathews Jr., K.H., Johnson, R.J. 2013. Alternative beef production systems: issues and implications. United States Department of Agriculture Economic Research Service. <http://www.ers.usda.gov/media/1071057/ldpm-218-01. pdf $>$ (Accessed 11.28.13).

McCall, D.G., Bishop-Hurley, G.J., 2003. A pasture growth model for use in a wholefarm dairy production model. Agric. Syst. 76, 1183-1205.

Menges, R., Schroeder, C., Traub, S., 2005. Altruism, warm glow and the willingness to-donate for green electricity: an artefactual field experiment. Environ. Res. Econ. 31, 431-458.

Mitchell, T.J., Beauchamp, J.J., 1988. Bayesian variable selection in linear regression. J. Am. Stat. Assoc. 83, 1023-1032.

National Research Council, 2000. Nutrient Requirements of Beef Cattle. National Academy Press, Washington, DC.

National Research Council, 2011. Sustainability and the US EPA. The National Academies Press, Washington DC.

National Research Council, 2013. Sustainability for the Nation: Resource Connection and Governance Linkages. The National Academies Press, Washington DC.

Nelson, J.P., Kennedy, P.E., 2009. The use (and abuse) of meta-analysis in environmental and natural resource economics: an assessment. Environ. Res. Econ. 42, 345-377.

Nilsson, T., Foster, K., Lusk, J.L., 2006. Marketing opportunities for certified pork chops. Can. J. Agric. Econ. 54, 567-583.

Pelletier, N., Pirog, R., Rasmussen, R., 2010. Comparative life cycle environmental impacts of three beef productions strategies in the upper midwestern United States. Agric. Syst. 103, 380-389.
Peters, G.M. et al., 2010a. Red meat production in Australia: life cycle assessment and comparison with overseas studies. Environ. Sci. Technol. 44, 1327-1332.

Peters, G.M., Wiedemann, S.G., Rowley, H.V., Tucker, R.W., 2010b. Accounting for water use in Australian red meat production. Int. J. Live Cycle Assessment 15, 311-320.

Rice, P.D., McLean, J., 1999. Sustainable Coffee at the Crossroads. Consumer's Choice Council, Washington, DC.

Romera, A.J., McCall, C.G., Lee, J.M., Agnusdei, M.G., 2009. Improving the McCall herbage growth model. N. Z. J. Agric. Res. 54, 447-494.

Rosen, S., 1974. Hedonic prices and implicit markets: product differentiation in pure competition. J. Polit. Econ. 82, 34-55.

Schulz, L.L., Schroeder, T.C., White, K.L., 2012. Value of beef steak branding: hedonic analysis of retail scanner data. Agric. Res. Econ. Rev. 41, 260-273.

Schweihofer, J.P. 2012. How much to expect when buying freezer beef: part one. Michigan State University Extension. <http://msue.anr.msu.edu news/how much to expect_when_buying freezer_beef part_one> (Accessed 11.28.13).

Stackhouse-Lawson, K.R., Rotz, C.A., Oltjen, J.W., Mitloehner, F.M., 2012. Carbon footprint and ammonia emissions of California beef production systems. J. Anim. Sci. 90, 4641-4655.

Teisl, M.F., Roe, B., Hicks, R.L., 2002. Can eco-labels tune a market? evidence from dolphin-safe labeling. J. Environ. Econ. Manage. 43, 339-359.

Tonsor, G.T., Shupp, R., 2009. Valuations of 'sustainably produced' labels on beef, tomato, and apple products. Agric. Res. Econ. Rev. 38, 371-383.

Tozer, P.R., Stokes, J.R., 2001. A multi-objective programming approach to feed ration balancing and nutrient management. Agric. Syst. 67, 201-215.

US Census Bureau. 2013. US Census Bureau International Data Base. US Deparment of Commerce.

Umberger, W.J., Feuz, D.M., Calkins, C.R., Killinger-Mann, K., 2002. US consumer preference and willingness to pay for domestic corn-fed beef versus international grass fed beef measured through an experimental auction. Agribuisness 18, 491-504.

United Nations. 2011. Department of Economic and Social Affairs, Population Division. World Population Prospects: The 2010 Revision, New York.

USDA/ERS. 2013. Retail prices for beef, pork, poultry cuts, eggs and dairy products. USDA/ERS.

Varela-Ortega, C., Sumpsi, J.M., Garrido, A., Blanco, M.A., Iglesias, E., 1998. Water pricing policies, public decision making and farmers' response: implications for water policy. Agric. Econ. 19, 193-202.

Viechtbauer, W., 2010. Conducting meta-analyses in R with the meta for package. J. Stat. Softw. 36, 1-48.

Vigani, M., Olper, A., 2013. GMO standards, endogenous policy and the market for information. Food Policy 43, 32-43.

Vorosmarty, C.J., Green, P., Salisbury, J., Lammers, R.B., 2000. Global water resources: vulnerability from climate change and population growth. Science 289, 284-288.

WCED, 1987. Our Common Future. Oxford University Press, New York, NY.

White, R.R., Capper, J.L., 2013. An environmental, economic and social assessment of improving cattle finishing weight or average daily gain within US beef production. J. Anim. Sci. 91, 5801-5812.

White, R.R., Johnson, K.A., Capper, J.L., 2013a. Exploring the production frontier 1. A multi-objective optimization of nutritional management to simultaneously minimize cost and environmental impact of beef production in the United States. Adv. Anim. Biosci. 4, 393.

White, R.R., Johnson, K.A., Capper, J.L., 2013b. Exploring the production frontier 2. A multi-objective optimization of pasture management to simultaneously minimize cost and environmental impact of beef production in the United States. Adv. Anim. Biosci. 4, 396.

World Bank. 2014. Data: GDP per capita (current US\$). <http://data.worldbank.org/ indicator/NY.GDP.PCAP.CD? page $=1>$.

Yu, X., Gao, Z. 2010. Consumer Preferences for US Beef Products: A Meta Analysis. In Proceedings of the Agricultural and Applied Economics Association 2010 Joint Annual Meeting. July 25-27, 2010, Denver, CO. 